\title{
20 On the Importance of Default Breach Remedies
}

\author{
Randolph Sloof \\ Hessel Oosterbeek \\ Joep Sonnemans
}




\section{Tinbergen Institute}

The Tinbergen Institute is the institute for economic research of the Erasmus Universiteit Rotterdam, Universiteit van Amsterdam, and Vrije Universiteit Amsterdam.

Tinbergen Institute Amsterdam

Roetersstraat 31

1018 WB Amsterdam

The Netherlands

Tel.: $\quad+31(0) 205513500$

Fax: $\quad+31(0) 205513555$

Tinbergen Institute Rotterdam

Burg. Oudlaan 50

3062 PA Rotterdam

The Netherlands

Tel.: $\quad+31(0) 104088900$

Fax: $\quad+31(0) 104089031$

Most TI discussion papers can be downloaded at http:/ /www.tinbergen.nl. 


\title{
On the Importance of Default Breach Remedies
}

\author{
by \\ Randolph Sloof, Hessel Oosterbeek and Joep Sonnemans*
}

Theory predicts that default breach remedies are immaterial whenever contracting costs are negligible. Some experimental studies, however, suggest that in practice default rules do matter, as they may affect parties' preferences over contract terms. This paper presents results from an experiment designed to address the importance of default breach remedies for actual contract outcomes. We find that default rules do have an impact. The reason for this is not that contract proposals and/or responses are biased towards the default, but rather that parties often disagree over what the best contract is and therefore end up with the default. (JEL: K 12, C 91)

\section{Introduction}

After a contract is signed, it may always occur that one of the parties fails to perform. Breach remedies make explicit what happens in this case. In particular, they either specify the exact amount of compensation the defaulting party has to pay to the victim of breach, or the way in which this amount is calculated. A large and mostly theoretical literature has emerged that investigates the attractiveness of various commonly used breach remedies, like liquidated damages, expectation damages, and reliance damages. The main focus is on whether these remedies induce efficient investment decisions and

*An earlier version of this paper was presented at the Experimental Law and Economics conference in Bad Meinberg (June 2006). The insightful remarks of the two discussants (Avishalom Tor and Urs Schweizer) and the other participants are gratefully acknowledged. 
efficient trade decisions (cf. Shavell [1980], Rogerson [1984]). The resulting efficiency ranking of the different breach remedies in general depends on the characteristics of the underlying trade relationship. ${ }^{1}$

Many real world contracts contain gaps and do not specify what happens if a party does not deliver as promised. In that case the parties involved (implicitly) rely on the default terms incorporated in the general contract law. These default rules apply in the absence of explicit contract terms to the contrary. An important issue is then which breach remedy should be chosen by legal policy makers as default. Traditional law and economics analysis starts from the celebrated Coase theorem, observing that in a world absent of contracting and bargaining costs, the choice of default remedy will have no impact on contractual relationships. Whenever the default remedy is inefficient, the parties to a contract will simply bargain around it and incorporate the efficient breach remedy into their contract. From this perspective the choice of default remedy should be guided by transaction cost considerations alone (see e.g. Posner [2003]).

Some experimental studies, however, suggest that default remedies may have an impact independent of contracting and bargaining costs. In an individual decision making experiment, Korobkin [2000] finds that expressed preferences for particular contract terms depend on the default terms in place. In particular, default terms create an "endowment effect", i.e. a higher stated valuation for a given term stemming from the mere fact that this term is part of the default. The explanation put forward is that subjects fear that they will suffer future regret from actively changing contract terms. In practice default rules are therefore likely to be "sticky", Korobkin argues, because parties will be reluctant to deviate from them even when there are no transaction costs in doing so.

Schwab [1988] investigates the impact of contract presumptions on contract bargaining in an experiment where subjects bargain with each other in pairs. Presumptions resemble default terms, as they "...interpret silent or ambiguous contracts but allow parties to alter or waive the presumed interpretation with specific language" ([Schwab, 1988, p. 239]). Standard theory predicts that presumptions neither have efficiency nor distributive effects. Partly in line with this, Schwab observes that presumptions do not affect

\footnotetext{
${ }^{1}$ Sloof, Leuven, Oosterbeek, and Sonnemans [2003] and Sloof, Oosterbeek, Riedl, and Sonnemans [2002] report results from laboratory experiments that by and large provide support for the efficiency ranking predicted by standard theory.
} 
the efficiency of bargains. However, they do affect the distribution of wealth; subjects are more successful in the negotiations when the presumptions are in their favor. Although Schwab did not explicitly include breach remedies in the contract presumptions he studied, his results do suggest that the "stickiness" of default breach remedies may be rather limited in practice. Even then though, they may affect the outcome of contract bargaining.

The above findings come from experiments in which no monetary incentives were provided. Moreover, in Korobkin [2000] subjects did not bargain with each other about the terms of trade whereas Schwab [1988] did not explicitly focus on breach remedies. In contrast, in this paper we consider an experimental setting with both interaction and monetary incentives, and we address the question of how default breach remedies affect the actual contract terms agreed upon head-on.

This paper proceeds as follows. In the next section we discuss the basic model on which our experiment is based. Section 3 describes the experimental design and formulates the hypotheses that are put to the test. Results are presented in Section 4. The final section summarizes and concludes.

\section{The model}

Two risk neutral parties, a female buyer and a male seller, may trade one unit of a particular good. In order to get the benefits from trade, the buyer must invest some resources before she learns whether the seller will deliver. Following Shavell [1984] this amount of reliance expenditures $r \geq 0$ is assumed to be fixed. The buyer's expectancy from trade equals $V>0$ whereas the seller's production costs are $c \geq 0$.

Apart from trading with the buyer, the seller has an alternative trading opportunity denoted $s$, with the (competitive) outside price $s$ unknown at the start of the relationship. We assume that $s$ is uniformly distributed on the interval $\left[s_{l}, s_{h}\right]$ (with $0 \leq s_{l}<s_{h}$ ). Throughout we also assume that profitable trades always exist, i.e. that $c<\max \left\{s_{l}, V\right\}$.

Efficiency requires that the seller trades with the original buyer whenever $s<V$ and sells to the outside buyer in case $s>V$. To make the situation interesting, we assume that $s_{l}<V$, so that breach is not always efficient. We also assume that $V<s_{h}$, such that separation is efficient in at least some contingencies.

The question of interest is whether the parties will arrive at the efficient outcome and trade only when it is efficient to do so. To govern their re- 
lationship the buyer and the seller may sign a contract $(p, \delta)$, stipulating a price $p \geq c$ the buyer has to pay in case of performance and a compensation amount $\delta \geq 0$ the seller has to pay in case of breach. More specifically, buyer and seller are assumed to play the following sequential-moves game:

I Contracting stage. Buyer and seller negotiate and sign a contract that specifies a fixed price $p \geq c$ the seller gets when the parties trade and a damage amount $\delta \geq 0$ the seller has to pay if he breaches the contract;

II Reliance stage. After the contract has been signed the buyer expends reliance resources $r$, with $r \in[0, V)$ fixed;

III Information stage. Nature draws the value of the seller's outside option $s$ from a uniform distribution on $\left[s_{l}, s_{h}\right]$. The value of $s$ becomes known to both parties;

IV Breach decision stage. The seller decides whether to trade with the original buyer, or to breach the contract. In the latter case the seller has to pay damage amount $\delta \geq 0$ to the buyer. ${ }^{2}$

Payoffs are as follows. When the seller trades with the original buyer, the seller gets $p-c$ whereas the buyer obtains $V-p-r$. In case the seller breaches the contract and goes to the outside buyer, the seller obtains $s-\delta-c$ while the buyer gets $\delta-r$.

The predicted outcome under a given contract $(p, \delta)$ is easily derived. Let $\Delta \equiv p+\delta$ denote the "gross" trade price, i.e. the seller's opportunity costs of breaching the contract. The seller then breaches whenever $s>\Delta$. Hence only when $\Delta=V$ the predicted outcome coincides with the efficient one. In case $\Delta<V$ the seller breaches too often from an efficiency perspective, because inefficient breaches happen whenever $\Delta<s<V$. For $\Delta>V$ too few breaches occur. In that case buyer and seller inefficiently trade if $\Delta>s>V$. Note that for all $\Delta \geq s_{h}$ breach does not occur. This formally corresponds with the remedy of specific performance, under which unilateral breach of contract is not possible. In the sequel we assume without loss of generality that $\Delta \leq s_{h}$ and we let $\Delta=s_{h}$ represent specific performance.

\footnotetext{
${ }^{2}$ Following Shavell [1980] we focus on the case where renegotiation of the initial contract is not possible. See Sloof et al. [2002] for an experimental comparison of various breach remedies in a setting that allows for renegotiation.
} 
In the contracting stage parties are expected to sign a contract that exhausts all possible gains from trade. For a given contract $(p, \delta)$ with $\Delta \equiv p+\delta \leq s_{h}$ it can be derived that expected joint payoffs equal:

$$
\Pi_{S}+\Pi_{B}=V-r-c+\frac{\left(s_{h}-V\right)^{2}}{2\left(s_{h}-s_{l}\right)}-\frac{(\Delta-V)^{2}}{2\left(s_{h}-s_{l}\right)},
$$

with $\Pi_{S}$ and $\Pi_{B}$ the expected net payoffs of seller and buyer, respectively. From the last term it is easily seen that joint payoffs are highest when $\Delta=V$. This corresponds with the expectation damages breach remedy $\delta=V-p$ under which the breach decision is always efficient. Price $p$ can be used as a separate instrument to distribute the gains from trade, and in such a way that both parties are willing to enter the relationship.

Overall, the equilibrium prediction is that parties will opt for the efficient expectation damages rule, independent of the default breach remedy in place. Exactly how the joint surplus is divided (i.e. how large price $p$ is) depends on the bargaining power of both parties at the contracting stage.

With the above expression for joint payoffs it is straightforward to rank, for a given price $p<V-r$, some commonly used breach remedies in terms of efficiency. As noted above, the expectation damages rule $\delta=V-p$ is first best. Because in our setting price $p$ is paid at the time the contract is performed, restitution damages correspond to the case of no damages $\delta=$ 0 . This breach remedy is (weakly) dominated by reliance damages $\delta=r$. However, because $p+r<V$ reliance damages does not attain first best as well. Under both reliance damages and restitution damages inefficiencies arise because the seller breaches too often. In case of specific performance breach of contract is not possible. Inefficiency then results from excessive performance and expected net social surplus equals $V-r-c$. Whether specific performance is more or less efficient than reliance damages depends

on how the problem of excessive performance compares to the problem of inappropriate breach. In general, this can go either way (cf. Shavell [1984]).

\section{Experimental design and hypotheses}

\subsection{Experimental game and treatments}

In the experiment we simplified the game of Section 2 by skipping the second reliance expenditures stage, i.e. we chose $r=0$. The remaining basic parameters were set equal to: $V=420, c=130, s_{l}=0$ and $s_{h}=700$. We also 
Table 1: Available contracts in the experiment

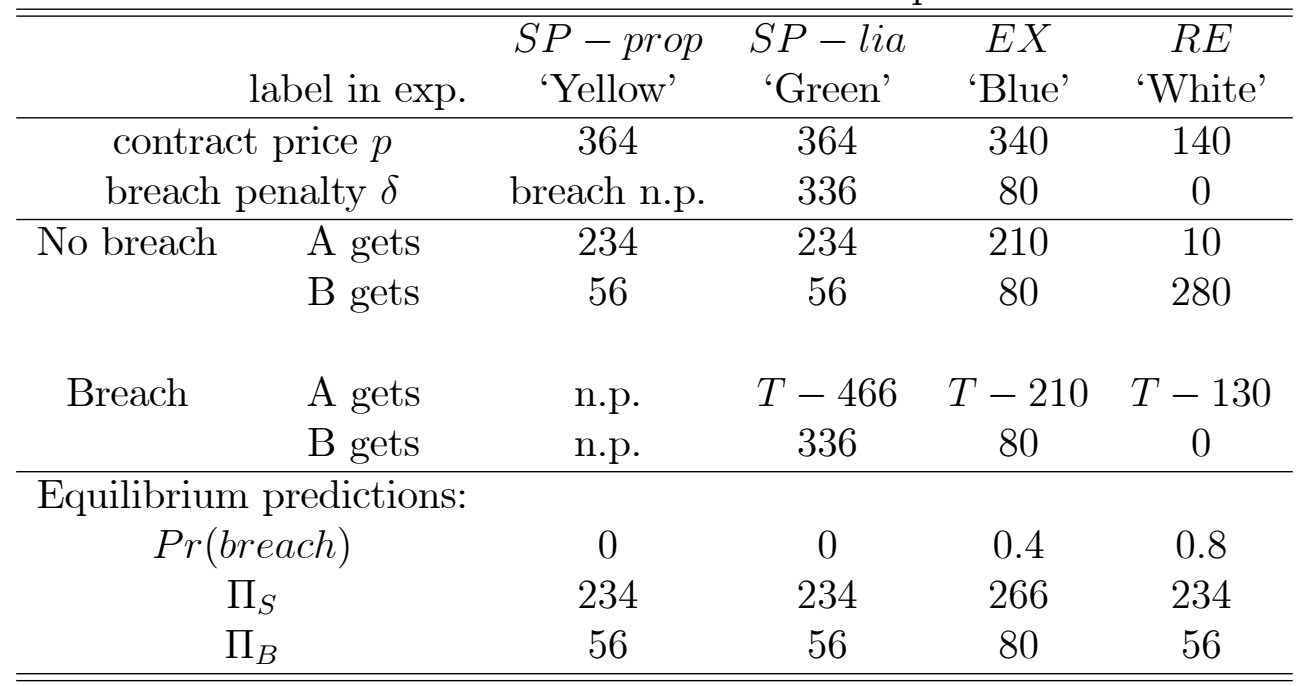

Remark: $V=420, r=0, c=130, s_{l}=0$ and $s_{h}=700 ;$ n.p. $=$ not possible.

restricted the parties' contract choices to just four different contracts $(p, \delta)$, see Table 1 for an overview.

We used colors as neutral labels to identify the available contracts. The 'blue' contract corresponds with expectation damages and is therefore also referred to as EX in the main text. Similarly, RE ('white') reflects both reliance and restitution damages, as for $r=0$ these two damage rules coincide. Specific performance is represented by two different contracts. In one of these breach of contract is explicitly excluded; breach is simply not an available choice option for the seller. This corresponds closest to an entitlement (to the seller's good) protected by a property rule and is therefore referred to as SP-prop ('yellow'). Under the second type of SP contract breach is possible in principle, but the damage amount due is set prohibitively high $\left(\Delta=s_{h}=700\right)$. This has the flavor of an entitlement protected by a liability rule and is thus denoted SP-lia ('green'). Although formally SP-prop and SP-lia are equivalent, the experimental findings of Rachlinski and Jourden [1998] on the endowment effect suggest that there may be an important psychological difference between the two. We therefore included them both.

We also used neutral labels for the seller (A) and the buyer (B) role. We did so to mitigate subjects' natural tendency of thinking that for the buyer (seller) the lowest (highest) price is always best. Alternative price $s$ was 
denoted $T$ in the experiment. The complete order of play was presented to the subjects as follows (the example below concerns the treatments where SP-lia, i.e. the 'green' contract, is the default):

1. One of the participants within a pair proposes a contract. S/he either chooses the default green contract, or one of the three alternative contracts referred to with the colors yellow, blue and white. Contracts differ in the price participant $\mathrm{B}$ has to pay to $\mathrm{A}$ in case $\mathrm{A}$ performs the contract and (if applicable) in the compensation amount $\mathrm{A}$ has to pay to $\mathrm{B}$ when $\mathrm{A}$ breaches the contract. The exact amounts belonging to a particular contract can be found in the table that is handed out to you [this table was similar to the upper two panels of Table 1];

2. If the contract proposal made in stage 1 deviates from the standard green contract, then the other participant within a pair decides whether to accept the proposed contract or not. When the proposal is rejected, or the default was proposed, the default green contract applies;

3. The computer picks amount $T$ at random, with each value between 0 and 699 being equally likely. Amount $T$ gives the alternative price participant A can get in case s/he breaches the contract;

4. Participant A decides whether or not to breach the contract. In case the yellow contract applies, breach of contract is not possible and this stage is skipped. When one of the other three contracts applies, participant A owes the relevant compensation amount to B in case of breach;

5. Per period payoffs are determined. The gross value B obtains when the contract is performed equals 420. The contract price has to be subtracted from this amount to obtain B's net payoffs. Participant A always bears fixed costs of 130 points. When the contract is performed the net payoffs of $\mathrm{A}$ are equal to the contract price minus these fixed costs. In case of breach of contract, B's net payoffs equal the compensation amount as specified in the contract. Participant A then obtains the alternative price $T$ reduced by both the compensation amount and the fixed costs of 130. The table handed out to you summarizes these payoffs [cf. the upper two panels of Table 1].

Each of the four available contracts was considered as being the default. Besides that, for each type of default contract we considered both the case 
in which the seller (A) proposes the contract and the one where the buyer (B) does so. Overall we thus used a 4 by 2 treatments design.

Clearly, in practice contract price $p$ is not part of the default breach remedy. Nevertheless we incorporated $p$ in the default contract besides compensation amount $\delta$, because we felt that allowing subjects to bargain separately about $p$ would make the experiment too difficult. Likewise, in reality the actual 'fall back' in case of disagreement is the situation without a contract. Yet having a contract with the default remedy as fall back strengthens the interpretation of this particular remedy as being the status quo. It thus gives the alternative non-Coasian prediction that default remedies may matter a fair chance. Another advantage of our setup is that there are no real costs to proposing a contract different from the default, because the proposer need not be afraid of ending up with no contract at all. S/he can thus safely propose his/her most preferred contract (but see the discussion of incentive compatibility below). This would not be the case if the situation without a contract served as fall back.

Given the above our experiment may be better interpreted as follows. Buyer and seller already agreed upon a price $p$, with the (implicit) understanding that the default breach remedy applies. They are currently drafting the contract and arrive at the paragraph which stipulates what happens in case the seller fails to perform. At this stage they may want to deviate from the default remedy and change the contract price accordingly, but only if both agree. If not, the default remedy with the original price $p$ applies.

\subsection{Experimental procedures}

In each session we kept the default contract fixed, in order to convincingly implement it as being the status quo. Within a session we varied the identity of the proposer, with the seller (subject A) taking up this role half of the time and the buyer (subject B) the remaining half of the time. We ran two sessions per default remedy, such that we had eight sessions in total. Overall 160 subjects participated, with 20 participants per session. The subject pool consisted of undergraduate students (mostly in economics) at the University of Amsterdam. They earned on average 26 euros in about $1 \frac{1}{2}$ hours.

Each session contained 20 periods. In each period the experimental game as described in the previous subsection was played. The 20 periods were divided into four blocks of five periods each. In each block the identity of the proposer was kept fixed. In one session per default remedy we used the order 
of A-B-A-B over the four blocks, in the other session the reverse order B-AB-A was used. This block structure allowed us to test for both learning and order effects. Subjects kept the same role during the whole experiment. In each single period they were anonymously paired. Within each block of five periods, subjects could meet each other only once and they were explicitly informed about that. Moreover, within each session subjects were divided into two separate groups of ten subjects that were independently matched. We did so to generate two independent group observations per session.

We provided all subjects with an initial endowment. Because sellers were expected to earn much more than buyers would do (cf. Table 1) and roles were kept fixed, we gave participants with role A an endowment of 1000 points and those with role B an endowment of 5500 points. The conversion rate was such that 300 points corresponded with 1 euro in money.

A potential disadvantage of our ultimatum game like contracting stage is that contract proposals are affected by anticipated acceptance behavior as well. In particular, the proposer may propose a second best contract when $\mathrm{s} /$ he thinks this contract is more likely to be accepted than her/his most preferred one. The actual contract proposals made thus do not measure the proposer's preferences in an incentive compatible way. Our design choice to have a particular given (default) contract as fall back instead of no contract at all mitigates this problem, but does not completely eliminate it.

With the above in mind we added a second part to the experiment, in which we measured subjects' preferences over contracts in an incentive compatible way. This part consisted of a single period only. Both seller and buyer were first asked to individually rank the four contracts from highest to lowest. The highest ranked contract got 20 points, the second highest 15 points, the third one 10 points and the fourth contract 5 points. After both had made their rankings, the points of buyer and seller for a particular contract were added and divided by 100 (i.e. the total number of points assigned). This gave the probability that this contract applied in the single period. Based on these probabilities, a random device subsequently determined the contract that actually applied. The game then continued with the draw of $T$ just as before, with the single exception that the period earnings were now multiplied by 5 to provide strong incentives. Besides incentive compatibility, the 'revelation' mechanism used in part two has the added advantage that it generates a complete preference ordering over contracts.

The equilibrium prediction that the efficient expectation damages contract will be implemented independent of the default remedy in place (cf. 
Section 2), hinges on the assumption of risk neutrality. When subjects are risk averse or risk loving, the predicted contract choices may change. In order to verify that possible differences between sessions (i.e. default remedies) cannot be explained by subjects' risk attitudes, we added a third part to the experiment. In this final part we measured subjects' risk preferences in an incentive compatible way similar to Holt and Laury [2002]. When discussing the results in Subsection 4.1 we describe this procedure in more detail.

The experiment took place over the computer. Subjects started with on-screen instructions (for the first part). All subjects had to answer some control questions correctly before the experiment started. They also received a summary of the instructions on paper. At the end of the first part subjects received new instructions for the second part, and similarly so at the beginning of the third part. At the end of the experiment the experimental points earned were exchanged for money and subjects were individually paid.

\subsection{Hypotheses}

According to standard theory risk neutral sellers and buyers prefer the efficient blue contract based on expectation damages over each of the other three contracts. This holds because the blue contract gives both parties their highest expected payoff, see the lower panel in Table 1. The prediction therefore is that the blue contract will be proposed and that this proposal will be accepted. This also implies that there is no role for the default contract.

Deviations from risk neutrality may alter these predictions. First consider the buyer. Under contract EX she obtains a payoff of 80 with certainty (see the middle panel in Table 1). The other contracts yield her only 56 in expectation. So the buyer's relative preference for EX becomes stronger when she is risk averse. Only when the buyer is very risk loving she will prefer RE over EX. This requires that she prefers a lottery of getting 280 with probability $\frac{1}{5}$ and 0 with probability $\frac{4}{5}$ over having 80 for sure.

For a risk averse seller contracts SP-prop and SP-lia become relatively more attractive. In these cases the seller is secured a payoff of 234. Under EX he bears some risk, because with probability $\frac{3}{5}$ he obtains 210 . There is a substantial upward potential though, because with probability $\frac{2}{5}$ he gets 350 in expectation. Hence only when the seller is very risk averse, he will prefer the SP contracts over expectation damages. Like for the buyer, also for the seller contract RE is a very risky option. This yields him 10 with probability $\frac{1}{5}$ and an expected value of 290 with probability $\frac{4}{5}$. 
Although deviations from risk neutrality may explain why parties prefer another contract than the efficient one, risk attitudes do not attribute any relevance to the default label per se. Parties value a contract independent of whether it constitutes the default or not. A mechanism that does attribute a direct role to the default contract is obtained when agents are motivated by the avoidance of future regret. Regret avoidance theory assumes that bad actions lead to more regret than bad inactions do (cf. Korobkin [2003]). Subjects will thus mentally assess the results of opportunities actively taken differently than those of opportunities not taken. In our setting it is natural to interpret choices different from the default as "actions" and choices for the default as "inactions". Bad inactions then result when the default contract turns out to be suboptimal ex post (as compared to the other three contracts), whereas bad actions occur when the new contract agreed upon appears worse than the default. Regret avoidance theory predicts that subjects especially try to avoid the latter type of bad outcomes.

Now, under regret avoidance default remedies are expected to be sticky. This holds because when specific performance is the default (i.e. either the yellow or the green contract), the seller may fear future regret from actively deviating from it. He would certainly regret such a decision whenever $T<$ 364 (cf. Table 1). In case of expectation damages (blue contract), the buyer may fear future regret (i.e. that $T<140$ materializes) . And under reliance damages (white contract), both parties may anticipate ex post regret. Given that it takes the consent of both parties to deviate from the default, parties are likely to stick with it. In particular, it will be more likely that a particular contract is proposed when it is the default than when it is not, and/or the default label per se will affect acceptance behavior.

Even when default contracts are unimportant for contract proposals and acceptance behavior, they may still affect actual contract choices. The reason is that in our setting the default contract will also be implemented when the parties disagree about the (most) preferred contract. According to standard theory and under risk neutrality such disagreement will not occur, because parties' incentives are perfectly aligned. Possible sources of disagreement are risk attitudes different from risk neutrality and regret avoidance. We will briefly discuss these two sources in turn.

When the seller is sufficiently risk averse he will prefer the SP contracts whereas these are never preferred by the buyer. When either the buyer or the seller is sufficiently risk loving s/he will prefer the RE contract, but this contract is never preferred by a partner who is not risk loving. Differences 
in risk attitudes thus provide ample opportunities for disagreement.

Disagreement may also stem from regret avoidance with respect to the ex post optimal contract. The seller is best off under the RE contract when $T>364$ whereas for $T \leq 364$ contracts SP yield him the most. Hence from this perspective the seller always suffers from ex post regret when the efficient contract is implemented. This does not apply for the buyer. She ex post prefers the efficient EX contract when $T>140$ and the RE contract when $T<140$. The two specific performance contracts are never ex post preferred by her, because these are strictly dominated by contract EX. Overall, for a seller who is motivated by regret avoidance the efficient EX contract is suboptimal. Yet the buyer is still likely to prefer this contract, yielding disagreement and implementation of the default contract. Note that this second type of regret avoidance is based on comparing the actually implemented contract with the ex post optimal one, rather than with the default contract.

\section{Results}

In presenting the results we pool the data from sessions that differ in the order of the party proposing the contract, because no order effects can be detected. We also aggregate over first and second halves of the sessions. Although some learning appears to take place, such effects are not very prevalent. ${ }^{3}$

\subsection{Contract proposals}

Table 2 gives the distribution of contract proposals by default contract and identity of the party making the proposal. We first consider the role of the default contract. Is it more likely that a particular contract is proposed when it is the default, than when it is not? The relevant information is on the diagonal of the table. It shows no prominent role of default contracts for proposals. Formal tests corroborate this. It is not more (or less) likely that a seller proposes the blue, green or white contracts when these are the default contracts than when they are not. Likewise, buyers do not propose the blue, yellow or white contracts more often when these are the default contracts than when they are not. Only when the yellow contract is the default, sellers are more inclined to propose it than when one of the other

\begin{tabular}{llll}
\hline${ }^{3}$ The test results on order effects and learning ef- \\
fects are reported in the web-appendix to this paper, see: \\
http://www1.fee.uva.nl/scholar/mdw/sloof/DefaultBreachAppendix.pdf.
\end{tabular}


Table 2: Proposals by default contract - Seller [Buyer] proposes

\begin{tabular}{cccccc}
\hline \hline Default & \multicolumn{4}{c}{ Proposed contract } & Total \\
\cline { 2 - 5 } & $\begin{array}{c}\text { SP-prop } \\
\text { 'Yellow' }\end{array}$ & $\begin{array}{c}\text { SP - lia } \\
\text { 'Green' }\end{array}$ & $\begin{array}{c}E X \\
\text { 'Blue' }\end{array}$ & $\begin{array}{c}R E \\
\text { 'White' }\end{array}$ \\
\hline Yellow & $79[4]$ & $11[64]$ & $76[98]$ & $34[34]$ & 200 \\
Green & $13[2]$ & $49[21]$ & $107[128]$ & $31[49]$ & 200 \\
Blue & $52[3]$ & $41[33]$ & $67[131]$ & $40[33]$ & 200 \\
White & $37[10]$ & $35[55]$ & $105[95]$ & $23[40]$ & 200 \\
\hline Total & $181[19]$ & $136[173]$ & $355[452]$ & $128[156]$ & 800 \\
Freq. & $.23[.02]$ & $.17[.22]$ & $.44[.57]$ & $.16[.20]$ & 1.00 \\
\hline \hline
\end{tabular}

contracts is the default. Buyers, however, are less inclined to propose the green contract when this is the default contract than when one of the other contracts is the default. In sum we can formulate the first result. ${ }^{4}$

Result 1: Default contracts are mostly unimportant for proposals.

Standard theory predicts that risk neutral buyers and sellers will always propose the efficient EX contract, because this gives each party the highest expected payoff. This is clearly not the pattern we observe in Table 2. Around half of all proposals deviate from the EX contract. Sellers spread these deviating choices roughly equally over the other three contracts. Buyers tend to avoid the yellow contract, which is expected because for them the yellow contract is strictly dominated by the blue contract.

Deviations could be reconciled with standard theory if subjects' risk attitudes deviate sufficiently from risk neutrality. To test this, in the third part of the experiment we measured risk aversion in the same way as Holt and Laury [2002] do. Subjects are given ten choices between a safe lottery and a risky lottery. (One randomly selected choice is actually paid out; see the web-appendix for more details.) A number of safe choices equal to 4 corresponds with risk neutrality. We subtract this number of 4 from the actual number of safe choices to arrive at our measure of risk aversion. A value of 0 then indicates risk neutrality and positive (negative) values indicate risk aversion (risk loving). The average level of risk aversion in our subject pool according to this measure equals $1.6(s . d .=1.66)$.

\footnotetext{
${ }^{4} \mathrm{P}$-values from ranksum tests for differences in proposals (and actual contracts) by default contract are presented in the web-appendix.
} 
Table 3: Regressions of number of contract proposals on risk aversion

\begin{tabular}{cccccc}
\hline \hline Proposed & \multicolumn{2}{c}{ Sellers } & & \multicolumn{2}{c}{ Buyers } \\
\cline { 2 - 3 } \cline { 5 - 6 } contract & intercept & coefficient & & intercept & coefficient \\
\hline Yellow & $1.53^{* * *}$ & $0.42^{*}$ & & $0.28^{* * *}$ & -0.03 \\
& $(0.55)$ & $(0.25)$ & & $(0.09)$ & $(0.04)$ \\
Green & $1.91^{* * *}$ & -0.12 & & $2.22^{* * *}$ & -0.04 \\
& $(0.41)$ & $(0.18)$ & & $(0.33)$ & $(0.15)$ \\
Blue & $4.35^{* * *}$ & 0.05 & & $5.61^{* * *}$ & 0.03 \\
& $(0.66)$ & $(0.29)$ & & $(0.42)$ & $(0.19)$ \\
White & $2.21^{* * *}$ & $-0.35^{* *}$ & & $1.88^{* * *}$ & 0.05 \\
& $(0.38)$ & $(0.17)$ & & $(0.27)$ & $(0.17)$ \\
\hline \hline
\end{tabular}

Remark: $* / * * / * * *$ indicates significance at the 10/5/1\%-level.

Standard errors appear in parentheses.

We regressed the number of times that a subject proposed each of the four contracts (ranging from 0 to 10, and adding up to 10) on her/his level of risk aversion. Results are reported in Table 3. For each proposer type we imposed the restriction that the intercepts add up to ten whereas the risk aversion coefficients add up to zero. The results indicate that sellers' proposals can to some small extent be explained by their risk attitudes whereas buyers' proposals are unrelated to their (measured) risk preferences. Because we scaled the risk aversion measure such that a value of zero corresponds with risk neutrality, we can interpret the intercepts as the choice frequencies under risk neutrality. These frequencies closely track the actually observed frequencies reported in the bottom row of Table 2. We therefore conclude that risk attitudes cannot explain the deviations from the efficient contract proposal.

Table 2 also reveals that buyers propose the efficient contract more often than sellers do. In particular, 44 percent of sellers' proposals and 57 percent of buyers' proposals equal the efficient contract. This difference is significant by means of a ranksum test $(p=0.0294)$. The same conclusion follows from comparing the intercepts reported in Table 3; the difference between 4.35 and 5.61 (blue contract) is significant at the $5 \%$ level. This indicates that the differences between buyers' and sellers' proposals are not driven by differences in risk attitudes. A more promising explanation here is regret avoidance. As explained in the previous section, sellers may want to deviate from the efficient contract if they try to avoid future regret. Ex post the efficient blue 
Table 4: Actual contracts by default contract - Seller [Buyer] proposes

\begin{tabular}{cccccc}
\hline \hline Default & \multicolumn{4}{c}{ Actual contract } & Total \\
\cline { 2 - 5 } & $\begin{array}{c}S P-\text { prop } \\
\text { 'Yellow' }\end{array}$ & 'Green' & 'Blue' & $R E$ & \\
& 'White' & \\
\hline Yellow & $104[79]$ & $10[40]$ & $73[61]$ & $13[20]$ & 200 \\
Green & $1[2]$ & $92[76]$ & $91[101]$ & $16[21]$ & 200 \\
Blue & $2[2]$ & $14[16]$ & $165[169]$ & $19[13]$ & 200 \\
White & $16[6]$ & $23[32]$ & $74[77]$ & $87[85]$ & 200 \\
\hline Total & $123[89]$ & $139[164]$ & $403[408]$ & $135[139]$ & 800 \\
Freq. & $.15[.11]$ & $.17[.21]$ & $.50[.51]$ & $.17[.17]$ & 1.00 \\
\hline \hline
\end{tabular}

contract is never optimal for them whereas this contract is optimal for buyers in a large number of contingencies (i.e. $T \in[140,700])$. Regret avoidance may thus explain the differences in proposals between buyers and sellers. We summarize these findings in the following result.

Result 2: Almost half of the proposals deviate from the efficient (blue) contract. Buyers propose the efficient contract more often than sellers do. These findings are not explained by (differences in) risk attitudes.

\subsection{Actual contracts and acceptance behavior}

Whether proposed contracts govern the relation between buyer and seller depends on the acceptance decision of the responder. Table 4 gives the frequencies of actual contracts by default contract and proposer type. From these tables we observe that slightly more than half of all relations is governed by the efficient (EX) contract. In each row we also see that for all default contracts and for both proposer types the frequencies of the default and the efficient contract are of very similar magnitudes. Formal tests corroborate this (see the web-appendix), which gives us the third result.

Result 3: The efficient (EX) contract and the default contract are equally likely to govern the relationship between buyer and seller. This holds for all default contracts and for both proposer types.

Obviously, if the default contract is proposed, it is also the actual contract. When another contract is proposed, the default contract still governs the 
relationship if the proposal is rejected. The previous subsection has shown that the default is not important for contract proposals. We now verify whether the default contract is important for acceptance behavior.

If the proposal differs from the default, the responder chooses between the proposed contract (by accepting the proposal) and the default contract (by rejecting). For each pair of contracts (say yellow and blue) we have observations where one of the contracts (say yellow) is the proposed contract and the other one (blue) is the default, and observations where these roles are switched (blue is proposed with yellow as default). This gives 2 by 2 tables in which we can test for equality by means of a chi-square test. This allows us to investigate whether a responder is more likely to choose a contract when it is the default than when it is not. We tested this for all pairwise combinations of contracts. Eight out of twelve comparisons are insignificant at the $5 \%$ level (see the web-appendix). In the remaining four cases the default contract is chosen significantly less often. There is thus some tendency for the responder to follow the proposer's suggestion to move away from the default. Overall, however, the following conclusion seems warranted.

Result 4: Acceptance behavior is not seriously affected by default contracts.

\subsection{Explaining stickiness}

The findings presented so far indicate on the one hand that neither proposers nor responders have a preference for the default contract per se (Results 1 and 4), while on the other hand relationships are often governed by the default contract (Result 3). This combination of results seems somewhat paradoxical. Our main explanation for this apparent paradox is that buyers and sellers often disagree about the (most) preferred contract and that disagreement puts the default contract in place.

Which of the four contracts a subject prefers is measured by two different methods in the experiment. The first method was already described in Section 3 when discussing experimental procedures. In the second part of the experiment we asked subjects to individually rank the four contracts from most to least preferred. The joint ranking of buyer and seller together then determined the probability that a given contract would be put in place. Columns (1) and (2) of Table 5 report the shares of buyers and sellers that put the different contracts first. It shows for instance that 68 percent of the buyers prefer the blue contract to all other contracts. These preferences do 
Table 5: Distribution of preferred contracts

\begin{tabular}{cccccc}
\hline \hline Contract & \multicolumn{2}{c}{ Revealed in part II } & & \multicolumn{2}{c}{ Revealed by proposals } \\
\cline { 2 - 3 } \cline { 5 - 6 } & buyers & sellers & & buyers & sellers \\
& $(1)$ & $(2)$ & & $(3)$ & $(4)$ \\
\hline Blue & 0.68 & 0.48 & & 0.64 & 0.48 \\
Yellow & 0.23 & 0.29 & & 0.00 & 0.20 \\
Green & 0.10 & 0.13 & & 0.15 & 0.14 \\
White & 0.09 & 0.11 & & 0.10 & 0.15 \\
ties & & & & 0.11 & 0.03 \\
\hline \hline
\end{tabular}

not differ significantly across default contracts.

The second method to measure preferred contracts is by looking at the frequencies of proposed contracts (cf. Subsection 4.1). In the first part of the experiment each subject makes ten contract proposals. From the observed frequencies we infer that the contract a subject proposes most often is her/his most preferred contract. Columns (3) and (4) of Table 5 report the shares of buyers and sellers that have the different contracts as their most preferred one according to this method. For example, 14 percent of the sellers proposes the green contract more often than any of the other three contracts. Because this second method does not exclude ties, a small fraction of buyers and sellers have multiple contracts in first place (cf. the row 'ties').

Because responders only have the choice (if any) between two different contracts, we also present information about revealed preferences between pairs of contracts. Here we actually have three sources of information. Besides the preferences revealed in part II and the frequencies of proposed contracts in part I, we now also have information from acceptance behavior. For each subject who as a responder was confronted with the choice between two contracts, we infer that the contract that was chosen most often is the preferred contract. Information is summarized in Table 6 .

Although the two methods employed in Table 5 do not give identical results, they by and large point in the same direction. The same is true for the three methods presented in Table 6 . The main insight that can be gained from these two tables is that it is quite likely that a buyer is confronted with a seller who has different preferences regarding the best contract. Moreover, within the group of buyers and within the group of sellers preferences over contracts are fairly heterogeneous. This makes it difficult for a proposing 
Table 6: Revealed pairwise preferences of contracts

\begin{tabular}{ccccccccc}
\hline \hline Contracts & \multicolumn{2}{c}{ Part II } & & \multicolumn{2}{c}{ Proposals } & & \multicolumn{2}{c}{ Acceptance } \\
\cline { 2 - 3 } & buyers & sellers & & buyers & sellers & & buyers & sellers \\
& $(1)$ & $(2)$ & & $(3)$ & $(4)$ & & $(5)$ & $(6)$ \\
\hline Blue $>$ Yellow & 0.96 & 0.58 & & 0.90 & 0.65 & & 0.94 & 0.56 \\
Blue $>$ Green & 0.83 & 0.71 & & 0.75 & 0.58 & & 0.76 & 0.59 \\
Blue $>$ White & 0.84 & 0.83 & & 0.74 & 0.61 & & 0.56 & 0.70 \\
Yellow $>$ Green & 0.13 & 0.46 & & 0.03 & 0.34 & & 0.00 & 0.45 \\
Yellow $>$ White & 0.50 & 0.69 & & 0.04 & 0.40 & & 0.40 & 0.48 \\
Green $>$ White & 0.68 & 0.71 & & 0.44 & 0.31 & & 0.55 & 0.54 \\
\hline \hline
\end{tabular}

party to predict the responder's preferences.

Consider, for example, a buyer who has to propose a contract and who prefers the blue contract over the other three contracts. When yellow is the default, there is a $44 \%$ probability that $\mathrm{s} /$ he meets a seller who prefers the yellow contract and thus will reject the proposal for blue (the $44 \%$ here is based on acceptance behavior, see column (6) in Table 6). Likewise, with green and white as defaults the probability that a blue proposal gets rejected is $41 \%$ and $30 \%$, respectively. The same type of reasoning applies to other preferred contracts by the buyer and to revealed preferences of the seller obtained by a different method. In all such cases of disagreement the default contract will govern the relationship. We summarize these findings as follows.

Result 5: Preferences over contracts are fairly heterogeneous. This easily leads to disagreement between proposer and responder, turning the default contract into the actual contract.

The final issue is whether stickiness matters from an efficiency perspective. In our simple setup without endogenously chosen reliance expenditures, efficiency is fully determined by sellers' breach decisions. The actual breach decisions appear very close to the predicted ones (due to space limitations the actual numbers are reported in the web-appendix). Therefore, the observed fraction of breaches under the different contracts are almost identical to the predicted breach probabilities (cf. Table 1). This in turn implies that efficiency is in line with the theoretical predictions and yields our final result.

Result 6: Breach decisions almost always maximize sellers' payoffs. Breach 
decisions are always efficient under the EX contract and very often inefficient under the other three contracts.

Because breach decisions are always efficient under the EX contract and implementation of this contract is more likely when it is the default, it follows that joint (as well as individual) payoffs are higher when the EX contract is the default than for any other default contract.

\section{Conclusion}

Standard economic theory predicts that default breach remedies are immaterial whenever contracting and bargaining costs are negligible. Some experimental studies, however, suggest that in practice default rules do matter, because they may affect parties' preferences over the various breach remedies. This paper presents results from an experiment designed to address the role of default breach remedies for actual contract outcomes. In contrast to previous studies the focus is on a setting with both explicit interaction between contracting parties and explicit monetary incentives.

In the experiment buyers and sellers have the choice between four different contracts. These contracts represent the remedies of expectation damages, reliance/restitution damages, specific performance protected by a property rule and specific performance protected by a liability rule, respectively. Contract negotiations take the form of ultimatum bargaining. Either the buyer or the seller proposes a contract. If the other party agrees, this contract governs their relationship. If not, the default contract applies. Sessions in the experiment differ in the contract that constitutes the default.

The design of the experiment is such that risk neutral buyers and sellers both earn the highest expected payoff under the efficient contract based on expectation damages. In principle parties thus could easily reach agreement. Yet, we observe that the efficient contract and the default contract are equally likely to govern the relationship. For actual contracts we thus find that default rules do have an impact and tend to be "sticky". The reason behind this is not that contract proposals or acceptance decisions are biased towards the default. Instead, the evidence indicates that the default contract often results because parties have different preferences regarding the best contract. While a majority of the buyers prefer the efficient contract, less than half of the sellers do so. Sellers' preferences for other contracts are not explained by their risk attitudes. A more promising explanation seems regret avoidance. 
Whereas the efficient contract gives sellers their highest expected payoff, ex post the actual payoff under this contract is always below the maximum attainable under one of the other three contracts. Hence, a seller who chose the efficient contract could ex post always have done better.

Because default remedies do matter even in our experimental world without bargaining costs, it matters which breach remedy serves the role of default. It is welfare enhancing when the default remedy minimizes inefficient breaches. Simply trusting that parties will replace inefficient default rules by an efficient one seems unwarranted.

Our findings are based on a design in which disagreement imposes the default contract and bargaining is in the form of an ultimatum game. Useful extensions of the current study include deviations from this design: viz. a situation where disagreement leads to no contract at all and more elaborate bargaining protocols. Both extensions may reduce the importance of the default and thereby qualify the conclusion based on the current design. ${ }^{5}$ Apart from that, it may also be useful to include individual measures of regret avoidance in future studies. This would enable a direct test of the above suggestion that regret avoidance drives a wedge between buyers' and sellers' most preferred contracts.

\section{References}

Fehr, E., S. Kremhelmer, and K. Schmidt (2005). Fairness and the optimal allocation of ownership rights. CEPR Discussion Paper No. 5369.

Holt, C. and S. Laury (2002). Risk aversion and incentive effects. American Economic Review 92, 1644-1655.

Korobkin, R. (2000). Behavioral economics, contract formation, and contract law. In C. Sunstein (Ed.), Behavioral law \& economics, Chapter 4, pp. 116-143. Cambridge: Cambridge University Press.

\footnotetext{
${ }^{5}$ Fehr, Kremhelmer, and Schmidt [2005] conduct an experiment on the optimal allocation of ownership rights. Subjects start from a given ownership structure, but may mutually agree to interact under a different one. In two treatments the game ends after disagreement about a change in ownership structure, in another one the game continues under joint ownership. The basic ownership pattern that results is the same in all these treatments, suggesting that the impact of the actual fall back may be rather limited.
} 
Korobkin, R. (2003). The endowment effect and legal analysis. Northwestern University Law Review 97, 1227-1293.

Posner, R. A. (2003). Economic Analysis of Law (6 ed.). Aspen Law and Business.

Rachlinski, J. and F. Jourden (1998). Remedies and the psychology of ownership. Vanderbilt Law Journal 51, 1541-1582.

Rogerson, W. (1984). Efficient reliance and damage measures for breach of contract. Rand Journal of Economics 15, 39-53.

Schwab, S. (1988). A coasean experiment on contract presumptions. Journal of Legal Studies 17, 237-268.

Shavell, S. (1980). Damage measures for breach of contract. Bell Journal of Economics 11, 466-490.

Shavell, S. (1984). The design of contracts and remedies for breach. Quarterly Journal of Economics 99, 121-148.

Sloof, R., E. Leuven, H. Oosterbeek, and J. Sonnemans (2003). An experimental comparison of reliance levels under alternative breach remedies. Rand Journal of Economics 34, 205-222.

Sloof, R., H. Oosterbeek, A. Riedl, and J. Sonnemans (2002). Breach remedies, reliance and renegotiation. Forthcoming in: International Review of Law and Economics.

All authors:

University of Amsterdam

School of Economics

Roetersstraat 11

1018 WB Amsterdam

The Netherlands

E-mail: r.sloof@uva.nl; h.oosterbeek@uva.nl; j.h.sonnemans@uva.nl 